of Italy and as the first Pleistocene deposits. These are conclusions that conflict with long-accepted ideas. J. Reid Moir had already challenged them in part in 1924, and recent work, based on a more critical determination of the fossil species, tends to show that the earlier correlations need revision. Thus, Dr. D. Wirtz's conclusions from his studies of the Mollusca of the Limonitsandstein of Sylt are in accord with those of Dr. Lagaaij. It is clear that Dr. Lagaaij has made an important contribution to the classification of the Plio-Pleistocene deposits by his detailed investigation of a much neglected group of fossils.

\section{BOATS THROUGHOUT THE AGES}

Boats and Boatmen

By T. C. Lethbridge. (The Past in the Present Series.) Pp. viii $+199+4$ plates. (London: Thames and Hudson, Ltd., 1952.) 15s. net.

MR. T. C. LETHBRIDGE brings to the writing VI of this book several special qualifications. Boats and their build and rigging have been his passion all his life, and what he does not know about their construction is not worth knowing. $\mathrm{He}$ is in the line of succession of H. H. Brindley and James Hornell. Himself an experienced sailor and explorer, he is also well known as an archæologist who speaks with particular authority on Anglo-Saxon times in eastern England-the result of years of excavation. To these specialist qualifications he adds the ability to make accurate thumbnail sketches in pen-and-ink showing clearly the differences in build and rig between the numerous kinds of craft he describes. It need scarcely be said, then, that "Boats and Roatmen" is a work full of interesting facts, well presented and well illustrated.

There are many theories adumbrated and suggestions thrown out. All of them are plausible, and doubtless a proportion of them are true. It is argued, for example, that experiments in construction took place in estuaries rather than elsewhere : it was not safe to play about with the received canons of boatbuilding if you were going to sail far out into the deep blue sea. Again, it is suggested that no ideas grew in the minds of the actual boatmen themselves. New possibilities developed in the imaginations of the directors and owners. As Lord Raglan once remarked apropos of anthropological matters, "the peasant never invented anything, the inventor was the man who set the peasant to work". It has been the warrior directing the fleet who will have been always experimenting to produce larger and faster craft. In the same way, it will have been the merchant and the fishmonger (rather than the fisherman) who have been trying out new ideas for the past two thousand years. Lethbridge also throws out many suggestions in the chapter on superstition and ritual, both as to the meaning of such signs as the oculus and the figurehead, and their regions of origin. I am not competent to pronounce in this field, and every student of such matters seems to have his own pet theory. But Lethbridge's ideas appear to the layman to be perfectly reasonable. I suppose he will be most criticized in his disparagement of the inventive genius of the northern folk, especially of the Vikings. He allows them clinker-building ; but suggests that most of the other developments seen in their craft were derived from the Mediterranean.

There are chapters on fishing and fishermen; superstition and ritual; the origin and development of boats in the West; how boats are propelled; the influence on boat design of beaches and estuaries. As has been said, each chapter is profusely illustrated with sketches. There is one big omission : the book lacks a glossary of technical terms arranged alphabetically. On p. 131 we are told a boat has heavy "quests". Alas, I do not really know what a quest is. A valiant attempt has been made in the early chapters to make the nautical jargon intelligible to the layman; but a glossary of terms would save much trouble and should be included in the second edition--which will certainly be called for.

M. C. BurkitT

\section{DIFFERENTIAL GEOMETRY OF CURVES AND SURFACES}

\section{Lectures on Classical Differential Geometry}

By Prof. Dirk J. Struik. Pp. viii+221. (Cambridge, Mass. : Addison-Wesley Press, Inc., 1950.) 6 dollars.

HIS book is based on a course given by Prof. D. J. Struik at the Massachusetts Institute of Technology. It gives a clear and attractive account of the differential geometry of curves and surfaces. A distinctive feature is the large number of diagrams, supplemented by a few photographs of models of surfaces. Another excellent feature is the abundance of historical and bibliographical notes, which not only stimulate interest, but also help students to refer to the original sources.

Chapter 1 explains vector notation, in the form used by Gibbs, and applies this to the properties of curves, their tangents, osculating planes, curvature, torsion, evolutes and involutes. Chapter 2 deals with the elementary theory of surfaces and their tangent planes, normals, and asymptotic and curvature lines. It includes an account of the first and second fundamental forms, the indicatrix, conjugate directions, and triply orthogonal systems of surfaces. Chapter 3 deals with the fundamental equations from the Gaussian point of view, including the equations of Gauss, Weingarten and Codazzi. The fundamental existence theorem of Bonnet is enunciated and explained ; but the general proof has been omitted as requiring too much knowledge of partial differential equations. Chapter 4, entitled geometry on a surface, opens with geodesics, geodesic curvature and geodesic co-ordinates. It then proceeds to the discussion of surfaces of constant curvature, non-Euclidean geometry, and the Gauss-Bonnet theorem concerning the integral of the geodesic curvature. Chapter 5 deals with some special subjects, including envelopes, conformal mapping, isometric and geodesic mapping, minimal and ruled surfaces, and the imaginary isotropic surfaces.

There is a large number of problems. Those in the text are easy, though of geometrical importance. A much harder set of twenty is given at the end of the book. These are really important theorems, and the student who finds them difficult can turn to the references given. The book concludes with answers to problems and hints for their solution, and with an index.
H. T. H. Piaggio 